\title{
ANNUAL REPORT ON \\ THE COLLABORATIVE PROGRAM OF RESEARCH IN ENGINEERING SCIENCES
}

September 1, 1990 to August 31, 1991

\section{DISCL.AIMER}

\begin{abstract}
This seport was prepared as an account of work sponsored by an agency of the United States Government. Neither the United States Government nor any agency thereof, nor any of their employees, makes any warranty, express or implied, or assumes any legal liability or responsibility for the accuracy, completeness, or usefulness of any information, apparatus, product, or process disclosed, or represents that its use wrould not infringe privately owned righis. Reference berein to any specific commercial product, process, or service by trade name, trademark. manufacturer, or otherwise does not necessarily constitute or imply its endorserment, recommendation, of fayoring by the United States Government or any agency thereof. The views and opinions of authors expressed herein do not necessarily state or reflect those of the United States Government or any agency thereof.
\end{abstract}

\author{
Energy Laboratory of the \\ Massachusetts Institute of Technology \\ in collaboration with the \\ Idaho National Engineering Laboratory
}

September 1991

MASTER

DSTRIBUTION OF Thro

DISTRIBUTION OF THIS DOCUMENT IS UNLIMITED 


\section{TABLE OF CONTENTS}

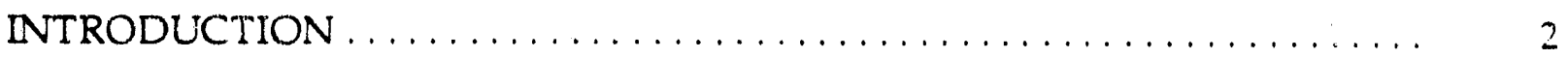

Research Progress Summaries . . . . . . . . . . . . . . . . . . . 2

Program Management. .......................... 4

SENSING \& CONTROL OF DROPLET-BASED THERMAL SYSTEMS . . . . . 8

Modeling and Control of Droplet Based Thermal Processes:

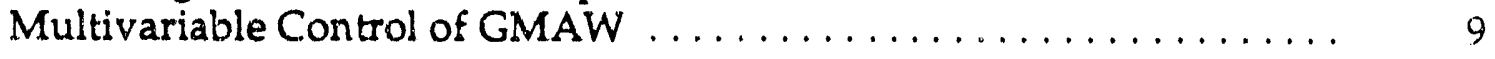

Metal Transfer Control in Gas-Metal Arc Welding $\ldots \ldots \ldots \ldots \ldots \quad 15$

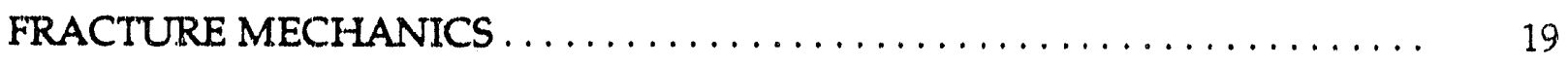

Fundamentals of Elastic-Plastic Fracture; Three-Dimensional

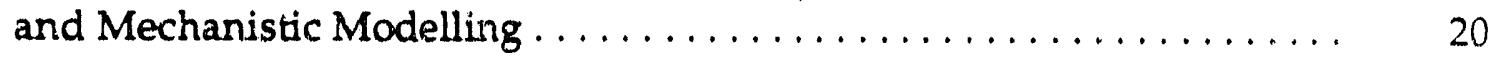

Comminution of Energy Materials $\ldots \ldots \ldots \ldots \ldots \ldots \ldots \ldots \ldots, 27$

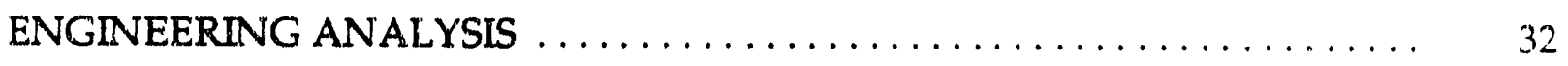

Synthesis and Optimization of Integrated Chemical Processes ...... 33

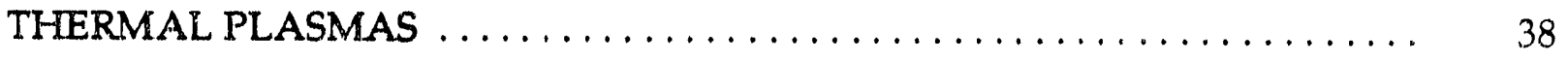

Mathematical Modeling of Plasma Systems . ............... 39

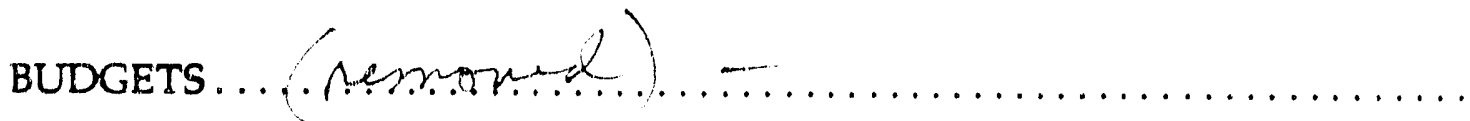




\section{INTRODUCTION}

In 1985, the Energy Laboratory of the Massachusetts Institute of Technology (MIT) and the Idaho National Engineering Laboratory (INEL) began a collaborative program of energy-related engineering research. This program was extended for another three years starting January 1991. The program continues to pursue three broad goals: to perform quality research on energyrelated technulogies involved in industrial processes and productivity; to demonstrate the potential of collaborative programs between universities and the national laboratories; and to encourage the transfer of the technology developed to the industrial sector. This annual report describes progress at MIT under the MIT/INEL program during the past year.

\section{RESEARCH PROGRESS}

Highlights of research activities and accomplishments during the past year include the following:

\section{Modeling and Control of Droplet Based Thermal Processes: Multivariable Control of GMAW}

Work on Multivariable Control of Gas-Metal Arc Welding during this period has concentrated on two main topics: depth estimation for realtime depth control and process modification for enhanced control. In the first case we have developed and successfully tested a depth estimator based on an inverse heat transfer model and surface temperature measurements that can accurately predict depth to within $\pm 15 \%$. New measurement methods for surface temperature have also been developed this year that should reduce the error below $10 \%$. Enhanced control of the process has been achieved by using high frequency transverse oscillation of the heat source. This allows greater control of the heat distribution and helps to decouple the bead geometry from the heat affected zone width. For both these cases we are proceeding with experiments exploring simultaneous two variable control. In the first case the variables are bead depth and width, and the latter bead width and heat affected zone widtl.

\section{Metal Transfer Control in Gas-Metal Arc Welding}

A new experiment has been designed and constructed which is being used to study new control techniques for metal transfer in gas-metal arc welding. The experiment uses mechanical energy as a new input to the welding process. The metal electrode is vibrated axially in order to aid in 
the detachment of metal drops. This experiment will be used to explore new modes of metal transfer and for testing new algorithms for detecting and controlling transitions between these modes.

Fundamentals of Elastic-Plastic Fracture; Three-Dimensional and Mechanistic Modelling

Tractable two-parameter elastic-plastic fracture mechanics methodologies are being developed and applied to provide improved descriptions of crack front stress and deformation fields. The so-called T-stress of linear elastic fracture mechanics has proven to be a useful correlator of varying crack tip stress triaxiality, and efficient numerical procedures for calculating $T$ have been developed. Computations show that the twoparameter formalism provides extremely accurate (within five percent) descriptions of the near-tip stress fields in a wide variety of plane strain, axisymmetric, and surface-cracked geometries over load levels ranging from well-contained yielding through limit load. The two-parameter approach has been shown to rationalize specirnen geometry effects in experimental measures of toughness for both cleavage initiation and ductile tearing. Simplified models for analysis of constraint-sensitive cracking in structures are being developed, based on micromechánical and mesomechanical scales.

\section{Comminution of Energy Materials}

Comminution, the reduction of coarse solids to fine particles, is a necessary step in coal cleaning and ore beneficiation, perhaps including oil shale. It is also a notoriously energy intensive process, particularly when grinding to the very small sizes necessary for deep cleaning of coal or for beneficiating low-grade ores. Comminution of material within deep particle beds is necessary for processing of sufficient mass flows of material. This project seeks to develop, through combined analytical and experimental work, an understanding of particle fracture and material transport mechanisms within such beds in order to develop designs of substantially increased efficiency. Computer simulation of beds of spherical particles has provided a clear picture of crushing behavior within beds. Experimental work with particle beds has qualitatively confirmed the simulation and provided quantitative data on crushing efficiency. Preliminary fluidized bed experimental work has demonstrated effective separation of fine material from coarse, an essential capability for the development of higher efficiency processes. Continuing analytical and experimental work will focus on the material transport and size separation behavior within fluidized beds suitable for use in a crusher. A novel crusher/material transport concept has evolved from this work and will continue to serve as a practical guide for these basic studies. 


\section{Synthesis and Optimization of Integrated Chemical Processes}

This research is aimed at developing improved computer methodologies for the design of integrated batch and continuous chemical processes. Batch processes are becoming increasingly important because of the increased emphasis of the chemical processing industry on higher value specialty chemicals. Methods for computer-aided synthesis and optimization of batch chemical processes have yet to reach an advanced state of development. Generic methodologies for simulation, optimization, and synthesis of batch processes will form the technology base on which the computer-aided engineering tools of the future need to be developed. This research is aimed at solving some key problems in this field.

In the area of continuous processes, work is focused on synthesizing processes with improved energy integration. The classical approach to complete flowsheet synthesis has been to decompose the problem into chemical process design, heat exchanger network design, and utility system design. The overall solution using this sequential approach neglects many subsystem interactions leading to inefficient use of capital, raw materials, and energy. This research focuses on developing a methodology for total flowsheet synthesis that takes into account subsystem interactions.

\section{Mathematical Modelling of Plasma Systems}

A comprehensive mathematical model is being developed to describe the electromagnetic, heat transfer, and fluid flow phenomena in plasma systems. At present a model of the plasma plume as well as the behavior of a non-transferred arc plasma torch has been developed and tested for a torch in the laminar mode of operation. The theoretical predictions of the model are in quite good agreement with experiments taken on this system at INEL. The work on torch behavior is currently being extended to turbulent systems, for which comparison is being performed with measurements made at INEL and other labs. Other work currently in progress includes the modelling of the laminarturbulent transition of the plasma jet, including engulfment phenomena, and the behavior of particles in such systems.

\section{PROGRAM MANAGEMENI}

Management of the program rests with a program manager from each of the two institutions. The INEL Program Manager is responsible to a program monitor at the Idaho Operations Office of the Department of Energy for 
ensuring adherence to c sst, scope, and sinedule for the INEL program. The INEL and MIT Program Managers interact with each other and with a program monitor in the Division of Engineering and Geosciences, Office of Basic Energy Sciences, Department of Energy.

Because the program entails objectives which go beyond the research results normally expected in such an effort, a committee system is in place to ensure that all objectives are met. Technical Advisory Committees, consisting of experts in the various fields of research, attend an annual, overall review of the program. (Reviews are held on alternate years at MIT and the INEL. The 1991 review was at INEL.) These Committees have played a key role in assessing technical progress of the program, as well as program direction and management. The Committees provide both oral and written reports of their findings to the Program Managers. The DOE program monitors also attend the oral presentations. The written reports are subsequently transmi'ted to the Principal Investigators. Views expressed by the Committees are taken very seriously and frequently serve as basis for changes in research techniques, new avenues of approach, and altered management procedures. Membership of these Committees, as of July 1991 is given in Table 1. A Steering Committee, consisting of representatives selected from the Technical Advisory Committees, has the charter of reviewing research progress, program managernent, quality of inter-laboratory collaboration, responsiveness to industry's long-term needs, and potential new research areas. In addition, technology obtained in the program is examined for appropriateness for transfer to industry. The Cornmittee is intended to establish mechanisms and industry candidates for technology transfer and implement means whereby MIT and INEL Principal Investigators and industry representatives can interact directly to assist in achieving program goals. Steering Conumittee members, as of July 1991 are listed in Table 2. 
Sensing and Control of Droplet

Based Thermal Sxstems

Dr. Hugh Casey*

Los Alamos National Laboratory

Professor David Olsen

Colorado School of Mines

Dr. Paul W. Ramsey

Ramsey and Associates

Mr. Howard B. Carey

Hobart Brothers Company

Dr. George E. Cook

Vanderbilt University

Mr. Richard Morris

David Taylor Research Center
Fracture Mechanics/Comminution/NDE

Professor Robert McMeeking

University of California, Santa Barbara

Dr. Sam S. Palusamy*

Westinghouse Electric Corporation

Dr. J.C. Newman, Jr.

NASA Langley Research Center

Dr. John Gudas

David Taylor Research Center

Professor Peter T. Luckie

Pennsylvania State University

\section{Thermal Plasma Processina/Fluid Flow}

Dr. C.W. Hirt

Flow Science, Inc.

Professor Emil Pfender

University of Minnesota

Dr. Thomas Meyer

ALCOA

Dr. Diran Apelian

Worcester Polytechnic Institute

Professor Pieter Stroeve

University of California

Dr. Merle Thorpe*

TAFA

- Steering Committeo Member 
TABLE 2. STEERING COMMITTEE

Sensing and Control of Droplet Based Thermal Systems

Dr. Hugh Casey

Los Alamos National Laboratory

Eracture Mechanics/Comminution/NDE

Dr. Sam S. Palusamy

Westinghouse Electric Corporation

\section{Thermal Plasma Processing}

Dr. Merle Thorpe

TAFA 
Sensing $\mathcal{E}$ Control of Droplet-Based Thermal Systems 


\section{MODELING AND CONTROL OF DROPLET BASED THERMAL PROCESSES: MULTIVARIABLE CONTROL OF GMAW}

\section{PERSONNEL}

Faculty: David E. Hardt, Laboratory for Manufacturing \& Productivity

Research Staff: Dr. Andre Sharon, Laboratory for Manufacturing \& Productivity

Graduate Students: Jae-Bok Song, Thomas Chuang, Radhouan Masmoudi

\section{ABSTRACT}

Work on Multivariable Control of Gas-Metal Arc Welding during this period has concentrated on iwo main topics: depth estimation for real-time depth control and process modification for enhanced control. In the first case we have developed and successfully tested a depth estimator based on an inverse heat transfer model and surface temperature measurements that can accurately predict depth to within $\pm 15 \%$. New measurement methods for surface temperature have also been developed this year that should reduce the error below $10 \%$. Enhanced control of the process has been achieved by using high frequency transverse oscillation of the heat source. This allows greater control of the heat distribution and helps to decouple the bead geometry from the heat affected zone width. For both these cases we are proceeding with experiments exploring simultaneous two variable control. In the first case the variables are bead depth and width, and the latter bead width and heat affected zone width.

\section{PROGRESS}

Estimation of Weld Depth from an Inverse Heat Transfer Model. In this work we have developed a real-time depth estimator for GMAW welding. The estimator uses surface temperature measurements to estimate the pool cross section by continuously solving and optimizing a heat conduction model. Within the model the weld heat source parameters are unknown, and must be found by matching model predicted temperatures with actual measurements. Through solution method and code optimization this method can now be executed in real-time (e.g. $5 \mathrm{~Hz}$ ).

The initial model included two heat sources so as to permit representation of GMAW "finger" penetration. Such a model requires both top and backside surface temperature measurements for calibration. However, early experiments demonstrated that the top surface and bottom surface temperatures are nearly decoupled, and that the latter alone are necessary for depth estimation in material 1/4" and thicker. Accordingly, we have adopted a backside sensing 
strategy that uses multiple points on the surface to provide data to the estimator. We have developed a dedicated measurement system based on multiple thermopile and total infrared spectrum sensing.

The basic results from this estimator are shown in Fig. 1. This data is from steady-state estimation trials, using both combined top and bottom side (dual source) sensing, and bottom side (lateral source) sensing. The plot represents a wide range of welding conditions on three thicknesses of $0.25,0.375$ and $0.5 \mathrm{in}$. From this data it is apparent that the depth can be estimated to within about $15 \%$ of the actual, and it is expected that the new sensing system will reduce this error further. Further details on this estimator can be found in Song and Hardt (1990).

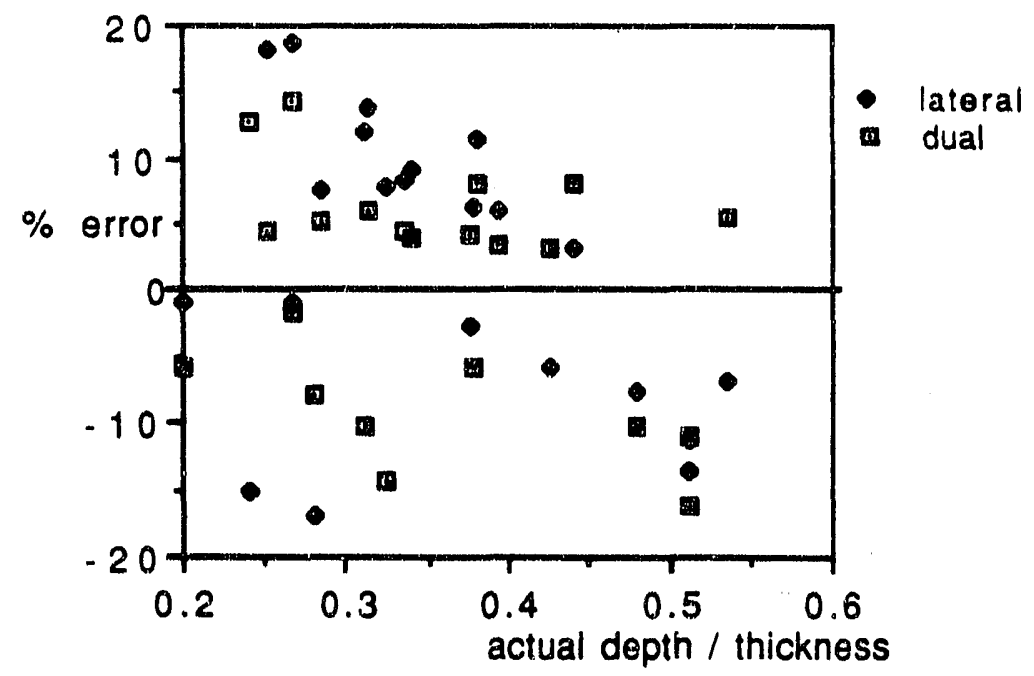

Fig. 1 Depth Estimator Resuits for Steady-State Experiments

Adaptive Multivariable Control of GMAW Width and Depth. Prior work on our project (Doumanidis and Hardt, 1989, 1990, and Hale and Hardt, $1990 \mathrm{a}, \mathrm{b})$ has conformed the non-linear nature of the welding process. As demonstrated by Suzuki and Hardt (1990) and Doumanidis and Hardt (1990), this non-linear behavior can be dealt with using either self-tuning control or model reference adaptive methods. In this work we have extended the earlier work of Doumanidis and Hardt, which dealt with temperature and temperature gradient control, and extended it to the faster and more strongly non-linear weld geometry problem. As detailed in Song and Hardt (1991), the one-step ahead adaptive method of Goodwin (1984) is used because of its applicability and designability for multivariable problems. However, to use this method for the geometry control problem, the parameter identification method had to be made faster than the more common "projection algorithm". Accordingly, the least square method was chosen and found to converge well using real welding data. 

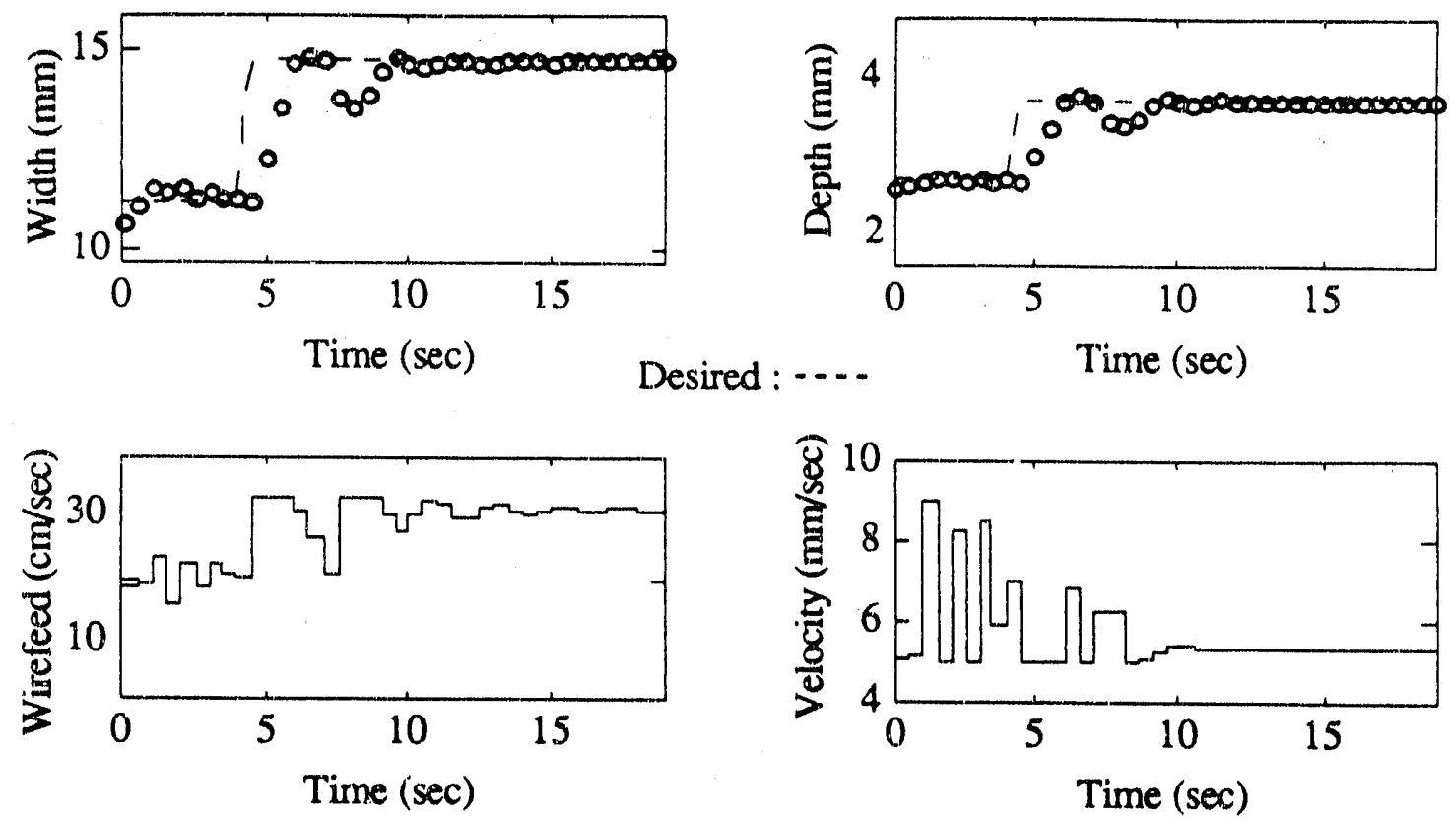

a) without control weighting
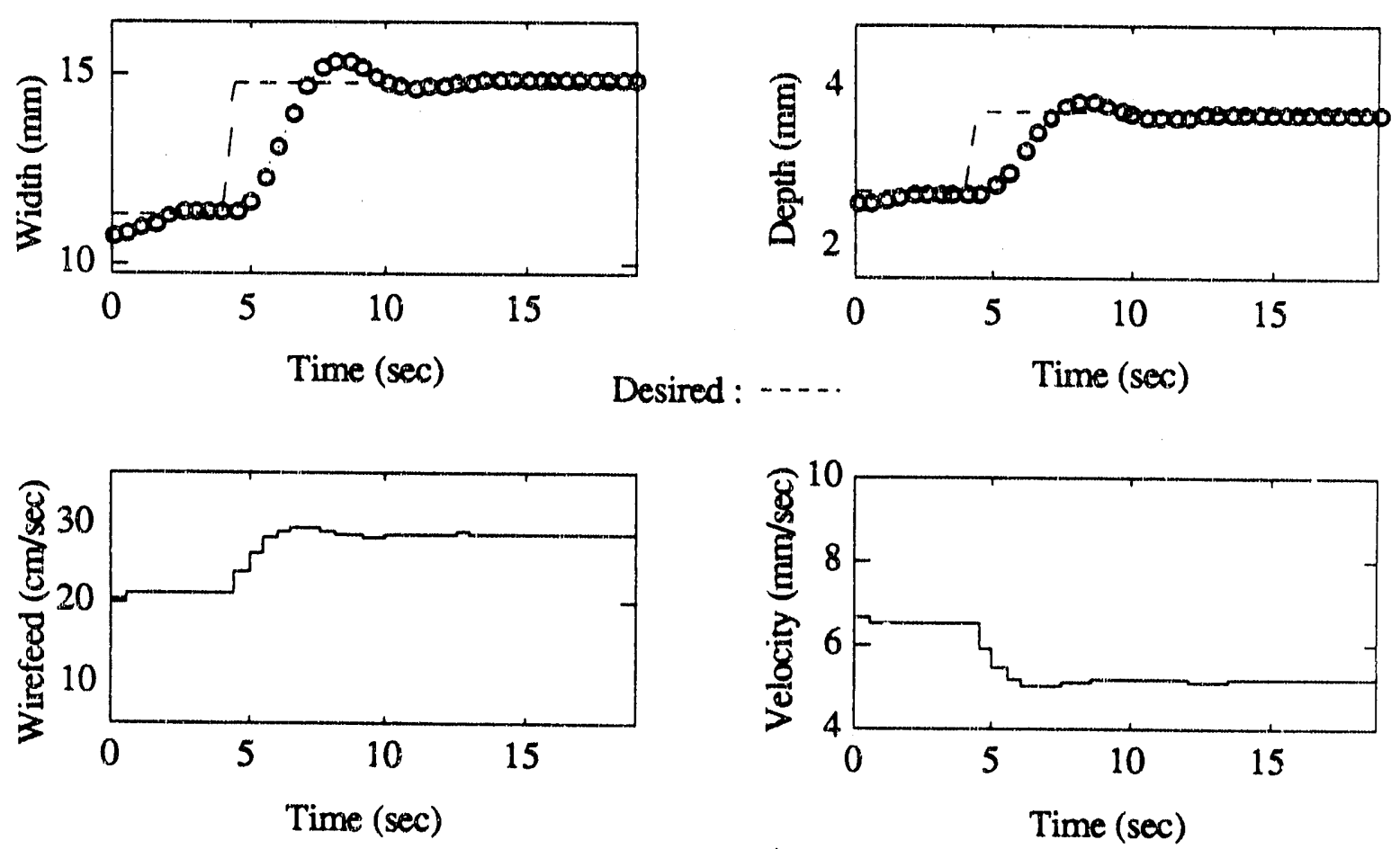

b) with control weighting

Fig. 2. Transient Response for Adaptive Control without (a) and with (b) Control Weighting. 
In addition. the one"step ahead method tends to expend excessive control effort, and the control weighting method of Goodwin was employed to yield favorable responses. A typical situation result using weighted control effort and the full non-linear welding model of Hale and Hardt (1990a) is shown in Fig. 2.

From this result it is apparent that smooth rapid regulation has been achieved for a prociss that has a strong input-dependent nonlinear behavior.

Experiments are now underway to combine the depth estimator and the video measurement of pool width into a multivariable control system. The adaptive controller of Fig. $2 b$ will be implemented and compared with a simple linear controller to maximize system performance with respect to regulation and tracking.

Process Modification for Enhanced Reachability. When multivariable control is aesirable, the inputs and outputs of choice must have sufficient range of operation to permit numerous operating points. However, as discovere $d$ by Hale and Hardt (1990a) the GMAW process is highly coupled for all input-output choices, and thus affords very limited process "reachability". The origit of this coupling is the basic process physics, primarily the use of a single heat source to heat the weldment and wire, and the coupled droplet and plasma momentum and magnetic field effects on the pool. Along with the efforts of Eagar, Lang and Jones, we have attempted to immediately broaden the range of the Bead Width/Heat Affected Zone Width output system through the use of high frequency low amplitude transverse weaving of the torch. This is intended to allow greater variation of the heat input distribution to the weldment and thereby allow independent control of the molten zone (e.g. bead width) and the heat affected zone. Early transient heat transfer models indicated that such an approach would significantly increase reachability of this output pair, and also indicated that the optimum weave frequency (for sinusoidal oscillations) was $\sim 10 \mathrm{~Hz}$.

We have performed an extensive series of simulations and experiments using both GMAW and GTAW to examine the effect of various inputs (weave frequency amplitude and overall travel speed) on the degree of decoupling of width and HAZ width. The simulation results are summarized in Fig 3. Without weaving, the input - output relationship is essentially a straight line indicating complete couping and low "reachability". However, with waving, the line expands to a large triangle, and multivariable control of these outputs now appears feasible.

Our current work involves experiments aimed at using this "new" system to demonstrate independent regulation of pool width and heat affected zone width. As with the pure geometry system, it is expected that non-linear behavior will require adaptive control techniques. 


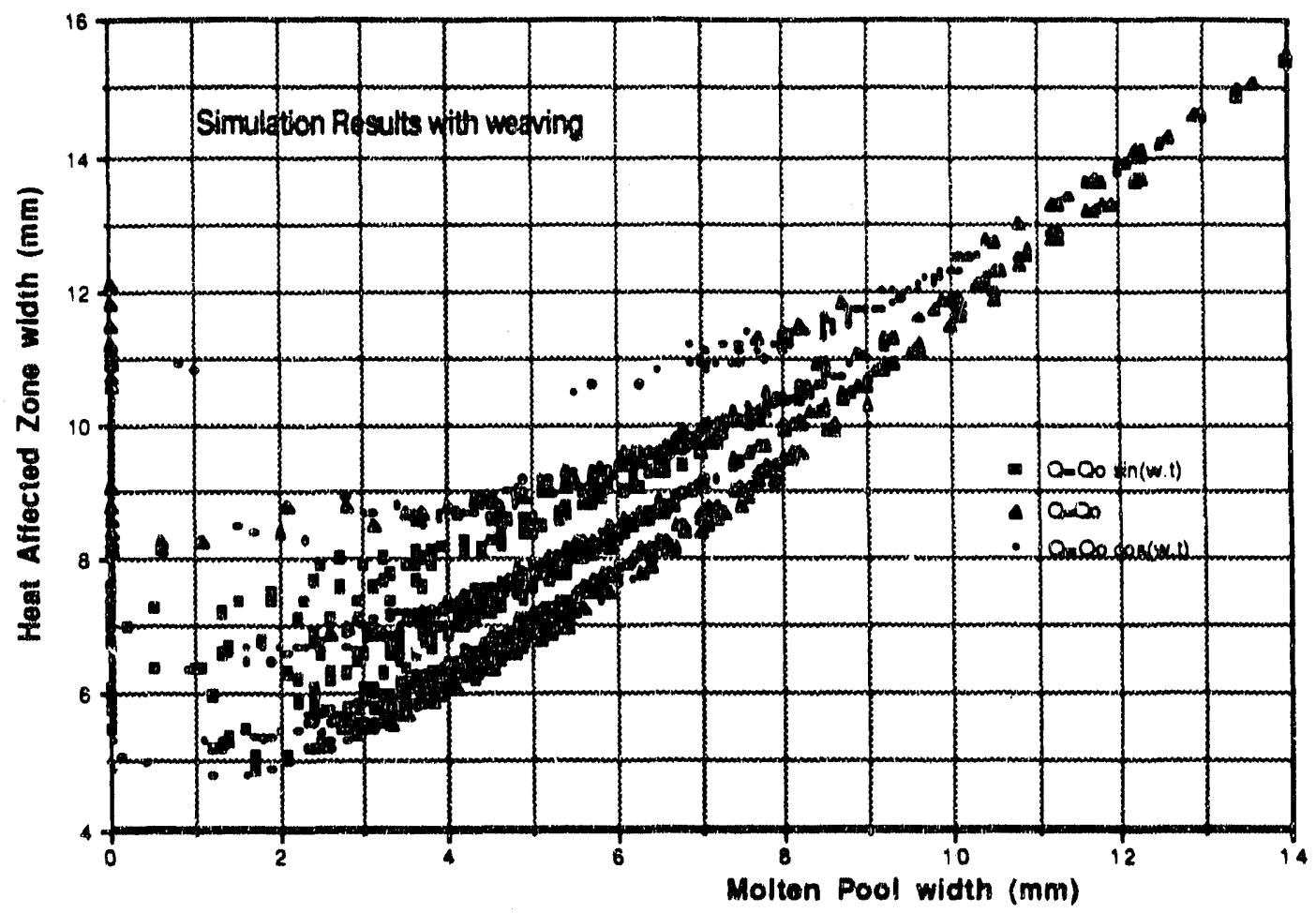

Fig.3 Reachability of Pool Width and Heat Affected Zone Width with High Frequency Weaving

\section{PROPOSED PLANS FOR THE YEAR IAN. 1, 1992 - DEC. 31, 1992}

In the coming year we expect to complete the two control experiments detailed above. At the same time we will launch a comprehensive effort at generalizing our modeling and control efforts on droplet based systems. In particular, the basic modeling approach taken to date: that of system identification and model tracking control will be carefully examined in the context of the general problem of phase-change/serial processes such as welding. The objective will be to determine the most appropriate modeling tools for control of this class of processes. $\mathbb{N}$ this phase we expect to collaborate closely with INEL owing to their work on the modeling methods of neural networks and fuzzy logic.

Since all droplet based systems, including welding are of a serial nature (see Hardt, 1991) for definitions) the proper independent variable for control can be either time or distance along the serial trajectory. This concept of time or distance based control, introduced in our original proposal, will be examined as part of this modeling effort. It is expected that this class of processes will provide an in-depth specific study for a larger program at MIT that is developing a general manufacturing process modeling and control methodology. 
To continue our efforts at enhanced process reachability and to enhance the measurability of the process, we plan to examine further process modifications, including those that completely decouple the base material heating from the filler material heating, and further attempt to control droplet production and placement. The objective here will be to greatly decrease the scale of molten material in any given region thereby increasing the spatial controllability of the process. In this work, we expect to collaborate with INEL on droplet size and velocity measurements, and on heat content data. It is anticipated that our effort will be joined by Prof. Jung-Hoon Chun of the Mechanical Engineering Department, whose work includes analysis of metal sprays, and development of well controlled particle size processes.

\section{REFERENCES}

Doumanidis, C.C. and D.E. Hardt (1989). A Model for In-Process Control of Thermal Properties during Welding. ASME Journal of Dynamic Systems, Measurement, and Control, Mar.

Doumanidis, C.C. and D.E. Hardt (1990). Multivariable Adaptive Control of Thermal Properties During Welding. ASME J. of Dynamic Systems Measurement and Control, 113, March, pp. 82-92.

Goodwin, G.C. and K.S. Sin (1984), Adaptive Filtering Prediction and Control. Prentice-Hall.

Hale, M.B. and D.E. Hardt (1990a). Multivariable Geometry Control of Welding - Part I: Process M'sdeling. Symposium on Manufacturing Process Modeling and Cuntrol. ASME, Dec.

Hale, M.B. and D.E. Hardt (1990b). Multivariable Geometry Control of Welding - Part II: Process Control. Symposium on Manufacturing Process Modeling and Control. ASME, Dec.

Hardt, D.E. (1990). Real-Time Process Control: Limits to Progress, in review ASME Manufacturing Reviews, Nov.

Song, J.B. and D.E. Hardt (1990). Estimation of Weld Bead Depth for InProcess Control. Symposium on Manufacturing Process Modeling and Control, ASME, Dec.

Suzuki, A., Hardt, D.E., and Valvani, L. (1990). "Application of Adaptive Control Theory to On Line GTA Weld Geometry Regulation," ASME J. of Dynamic Systems Measurement and Control, 113, March, pp. 93-103. 


\section{METAL TRANSFER CONTROL IN GAS-METAL ARC WELDING}

\section{PERSONNEL}

Faculty: T.W. Eagar, Department of Materials Science and Engineering J.H. Lang, Department of Electrical Engineering \& Computer Science

Graduate Students: L. Jones

\section{ABSTRACT}

A new experiment has been designed and constructed which is being used to study new control techniques for metal transfer in gas-metal arc welding. The experiment uses mechanical energy as a new input to the welding process. The metal electrode is vibrated axially in order to aid in the detachment of metal drops. This experiment will be used to explore new modes of metal transfer and for testing new algorithms for detecting and controlling transitions between these modes.

\section{GOAL}

The overall goal of the MTT-INEL welding research program is to investigate methods of automating and controlling the GMAW process. This problem is difficult because of the complexity of welding process. Overall control of the process involves control of metal transfer across the arc and control of the size and shape of the weld pool. This specific project has the objective of investigating new control techniques for improving the metal transfer process in gas-metal arc welding. It is anticipated that these new control methods will result in robust new weld operating modes with decreased energy use, increased operator safety, reduced metal fume emissions, and improved quality and productivity.

\section{PROGRESS}

Virtually complete decoupling of electrode melting rate and base-plate heating may be achieved using two power sources. Partial decoupling may be achieved by using only a single pulsed-current power source. The pulsing enhances the magnetic detaching force while allowing a lower average current. Higher metal deposition rates are observed when using pulsed current.

An additional phenomenon observed when using pulsed current is the production of less metal vapor. It is known that the temperature of the molten drops is substantially higher than the melting point. The higher detaching forces obtained using pulsed current reduce the amount of excess heat in the drops. The 
excess heating of the drops results in the production of metal vapor fumes. Additionally, more volatile constituents of the alloy are lost, which reduces the quality of the welding environment.

A system may be developed that uses the excess heat in the metal drops as a second power source. The melting rate may be changed independently from the base-plate heating by changing the amount of heat lost in metal vapor. To accomplish this, a system has been designed and constructed which mechanically vibrates the electrode longitudinally. Through the combined effects of current pulsing and mechanical acceleraticn it is possible to effect premature drop detachment, thereby preventing excess heating of the drop. The welding process is thus cleaner and more efficient.

The mechanical vibration of the electrode is accomplished using a electromechanical vibration table. A new wire pinch mechanism and electrode contact assembly were constructed which allow the force of vibration table to be transmitted to the electrode. In addition, a new computer control system based on the Texas Instruments TMS320C30 digital signal processor was assen bled and interfaced to the new welding equipment. The real-time computational capabilities along with the significant development software of this system is allowing the testing of control algorithms that synergistically combine current pulsing and mechanical vibration.

\section{PROPOSED PLANS FOR THE YEAR JAN. 1, 1992 - DEC. 31, 1992}

The new welding equipment constructed over the last year is, to our knowledge, unique and will allow us to perform experiments that will enhance knowledge of the physics of welding and explore new control systems. In particular, when using only pulsed current to effect premature detachment, the changing current and melting rate make it difficult to study the heat flow process. Using direct current and mechanical vibration, it will be possible, for the first time, to quantitatively confirm the theory that the metal drop insulates the solid electrode from the heat of the arc.

In order to utilize the new control input of mechanical vibration, methods of detecting the transitions between drop transfer modes will be further studied. Other researchers have showed that frequency-based filtering techniques are not effective. In pulsed-current welding, a square-wave component exists in both the current and the voltage which upsets linear filters. For drop detection, it is necessary to remove this square-wave component. A ranked-order filter such as the median filter is very effective for doing this. Ranked-order filters, and more generally morphological filters, will be investigated for detecting drop detachment and mode transitions. These filters are geometry-oriented and may be more useful than frequency-oriented filters.

With vibration control input and the ability to sense metal transfer modes, a complete metal transfer control system will be designed. The appropriate 
control criterion need to be developed. The inputs to the controller are information about drop detachment and transfer mode derived from voltage and current measurements. With this information, the controllar will set the current pulsing and mechanical vibration parameters.

\section{RECENT PUBLICATIONS}

Karl, W.C., S.B. Leeb, L.A. Jones, G.C. Verghese, J.L. Kirtley. "Applications of Ranked-base Filters in Power Electronics", accepted to IEEE Transactions on Power Electronics.

Sorensen, C.D. and T.W. Eagar. "Modelling of Oscillations in Partially Penetrated Weld Pools", J. Dynamic Systems and Control, 112(9), 463, 1990.

Sorensen, C.D. and T.W. Eagar. "Measurement of Oscillations in Partially Penetrated Weld Pools Through Spectral Analysis", J. Dynamic Systems and Control, 112(9), 463, 1990.

Kim, Y-S., D. McEligot, T.W. Eagar. "Analyses of Electrode Heat Transfer in Gas Metal Arc Welding", Welding J., 70(1), 20s, 1991.

Eagar,T.W. "An Iconoclast's View of the Physics of Welding - Rethinking Old Ideas", Recent Trends in Welding Science and Technology, S.A. David and J.M. Vitek, ed., ASM, Materials Park, OH, 341, 1990.

Kim,Y-S. and T.W. Eagar. "Temperature Distribution and Energy Balance in the Electrode During GMAW", Recent Trends in Welding Science and Technology, S.A. David and J.M. Vitek, ed., ASM, Materials Park, OH, 13, 1990.

Eickhoff, S.T. and T.W. Eagar. "Characterization of Spatter in Low Current GMAW of Titanium Plate", Welding J., 69(10), 382s, 1990.

Kim, Y.S. and T.W. Eagar. "Metal Transfer in Pulsed Current GMAW", submitted to Welding $J$.

Eagar, T.W. "The Physics of Welding Processes", Proceedings of the 5th International Symposium of the Japan Welding Society on Advanced Technology in Welding, Materials Processing and Evaluation, Makuhari, Tokyo, Japan, 17-19 April 1990.

Eagar, T.W. "Challenges in Joining Emerging Materials", Advances in Joining Newer Structural Materials, Proceedings from International Conference held in Montreal, Canada, July 23-25, 1990, Pergamon Press, Oxford, 3, 1990 (English and French).

Eagar, T.W. "Physics of Arc Welding Processes", Advanced Joining Technologies, Proceedings of the International Institute of Welding Congress on Joining Research, July 1990, T.H. North, ed. Chapman and Hall, London, 61, 1990. 
Eagar, T.W. "Whither Advanced Materials", Advanced Materials \& Processes, June 1991, pp. 25-29.

Eagar, T.W. "The Future of Metals", Welding J., 70(6), 69, 1991.

Kim, Y-S. and T.W. Eagar. "Analysis of Metal Transfer in Gas Metal Arc Welding", submitted to Welding $J$.

Ohji, T. and T.W. Eagar. "Infrared Radiation of Arc Plasma and Its Application to Plasma Diagnostics", submitted to Journal of Plasma Physics and Chemistry.

"Structural Steels", J.M. Barsom, T.W. Eagar, H.W. Paxton, R. Jaffee Symposium, Monterey, CA January 1991. 


\section{Fracture Mechanics}




\title{
FUNDAMENTALS OF ELASTIC-PLASTIC FRACTURE; THREE-DIMENSIONAL AND MECHANISTIC MODELLING
}

\author{
PERSONNEL \\ Faculty: $\quad$ D. M. Parks, Department of Mechanical Engineering \\ F. A. McClintock, Department of Mechanical Engineering \\ Research Staff: Y. Wang, Department of Mechanical Engineering \\ H. Lee, Department of Mechanical Engineering \\ Y. Kim, Department of Mechanical Engineering \\ S. Dhar, Department of Mechanical Engineering \\ Collaborators: J. W. Hancock, University of Glasgow \\ T. Nakamura, SUNY at Stony Brook \\ C. Betegon, University of Oviedo (Spain)
}

\section{ABSTRACT}

Tractable two-parameter elastic-plastic fracture mechanics methodologies are being developed and applied to provide improved descriptions of crack front stress and deformation fields. The so-called T-stress of linear elastic fracture mechanics has proven to be a useful correlator of varying crack tip stress triaxiality, and efficient numerical procedures for calculating $T$ have been developed. Computations show that the two-parameter formalism provides extremely accurate (within five percent) descriptions of the near-tip stress fields in a wide variety of plane strain, axisymmetric, and surface-cracked geometries over load levels ranging from well-contained yielding through limit load. The twoparameter approach has been shown to rationalize specimen geometry effects in experimental measures of toughness for both cleavage initiation and ductile tearing. Simplified models for analysis of constraint-sensitive cracking in structures are being developed, based on micromechanical and mesomechanical scales.

\section{GOALS}

We seek to accurately predict fracture in surface-cracked pressure vessels and piping (plates or shells), especially under plastic overloads as in accidents or earthquakes. This may involve through-cracking followed by lateral growth. For practical reasons, the modeling is being done down to the millimeter scale, which is the roughness of macroscopic cracks, rather than at the $0.01 \mathrm{~mm}$ scale of the void growth or cleavage facets. 


\section{PROGRESS}

Detailed finite element analysis of surface-cracked plates, Wang, et al, [1] compared finite element analysis of surface-cracked plates with detailed experimental measurements made at INEL. This joint MIT/INEL publication showed excellent agreement between calculated and measured (e.g., Moire) surface displacements, crack front opening displacement profile, etc. The agreement provides confidence in the calculations of substantial loss of crack front stress triaxiality, as previously reported in [2].

Two-parameter characterization of surface cracked plates, Wang, [3] analyzed surface-cracked plates containing deep $(a / t=0.6)$ and shallow $(a / t=0.15)$ cracks, subject to either remote tension or bending loads ranging from small-scale yielding to limit load. He showed that the local stress and deformation at distances from the crack front of order crack opening displacement were wellcharacterized by local values of J-integral and normalized T-stress. The decreasing stress triaxiality with increasing load noted in [2] had been interpreted by Parks [4] in terms of the T-stress, but Wang's calculations are both more precise and more extensive.

Determination of limits of applicability of (J,T) two-parameter descriptions of crack tip fields. Visitor, Dr. C. Betegon, initiated study of the limits of applicability of $(\mathrm{J}, \mathrm{T})$ descriptions of crack tip fields for a wide range of plane strain and axisymmetric crack configurations. Descriptions are invariably correct qualitatively, and are generally quite accurate quantitatively (predicted crack tip stress levels are with 10\%) through limit load. This work has continued with Wang and collaborator Hancock. We expect to publish these results, as well as guidelines for usage of $(\mathrm{J}, \mathrm{T})$ approaches, during the next year.

T-based correlation of constraint-sensitive ductile tearing. With Hancock of Glasgow and Reuter of INEL, we showed [5] how the T parameter continuously correlates the early slope of J vs. crack extension curves in a broad range of through-cracked and surface-cracked specimens spanning a wide range of crack tip stress triaxiality. Specimen geometries with strongly positive T-stress (compact tension; deeply-cracked bend specimens) showed lowest tearing slopes, while those with the most negative $T$-stress (center-cracked tension; shallow-cracked beind) showed highest tearing slopes. This trend closely follows the corresponding variation with $\mathrm{T}$ in crack tip stress triaxiality.

Line-spring estimates of $T$-stress for surface-cracked plates and shells. Wang and Parks [6] showed how the line-spring model [7] for analysis of surfacecracked plates and shells could be adapted for accurate estimation of the variation of T-stress along the crack front. Recently staff member, H. Lee, applied the method to a wide-arc part-through circumferential flaw in a pipe subject to bending, and obtained extremely negative T-stress levels. This observation correlates well with recent detailed three-dimensional finite element studies of this geometry which show extreme loss of crack front stress triaxiality in the plastic range. 
Domain-based interaction integrals for calculation of $T$-stress, Nakamura and Parks [8] generalized a method for evaluation of T-stress due to Eshelby which had been introduced by Kfouri [9]. The method was generalized to 3-D geometries and recast as a domain interaction integral analogous to those introduced previously [10] for evaluation of $\mathrm{K}_{\mathrm{I}}, \mathrm{K}_{\mathrm{II}}$, and $\mathrm{K}_{\mathrm{III}}$. The method permits evaluation of $T$-stress in arbitrary bodies with no more computational effort than in the now-standard domain integral/virtual crack extension methods for evaluating J. Interestingly, they found that the thin elastic plate geometry considered in $[11,12]$ has an inherently positive T-stress; this fact may partially account for the surprising resistance to loss of crack front stress triaxiality in the thin ductile plate of [12], even when the plastic zone reached sizes of order plate thickness, a condition where idealized plane stress models of low triaxiality are often invoked.

Extreme-value statistical models of cleavage micromechanics and effects of T-stress on cleavage initiation toughness, Wang, [13], in his doctoral thesis, showed how extreme value statistical treatments of cleavage fracture initiating in the plastic zone of a macroscopic crack could explain specimen geometry effects on initiation toughness $[14,15]$ through the effects of T-stress on local maximum principal stress.

Development of simplified models of surface cracks. The flow theory plasticity line-spring model of Parks and White [16], as currently implemented in the ABAQUS [17] commercial finite element code, is being enhanced in four important ways. Staff member $\mathrm{H}$. Lee has incorporated an effective crack length formulation to improve compliance and J estimates in moderate to large scale yielding. Using finite element limit analysis, he has developed numerical representations of cracked yield surfaces which, for shallow cracks $(a / w<0.35)$, greatly improve the deep crack estimates of Rice [18]. Lee has also developed improved models of ligament-averaged work-hardening in the fully plastic range. Working with staff member Kim, Lee is further generalizing the linespring to model constraint-sensitive through-thickness cracking.

Micromechanical modeling of crack growth in rigid-plastic, non-hardening materials. Mechanisms controlling crack growth are hole nucleation, growth, the localization of surrounding flow, and a decohering region that models the threedimensional crack roughness.

With sufficient crack growth in a fully-plastic, non-hardening material, the elastic strain increments make a negligible contribution [19]. Thus rigid-plastic, non-hardening fields are valid for growing cracks, and crack tip fields are characterized by the slip-line fields for stationary cracks. For fields with a pair of symmetric slip-lines, the flanks of the decohering zone turn out to be rigid and the derohering zone does not affect the crack tip opening angle (CTOA), which then must depend only on the micromechanisms of hole nucleation, growth, and localization. These mechanisms are in turn controlled by the near-field plasticity parameters: the slip angle $\theta_{\mathbf{s}}$ and the normal stress across it, $\sigma_{s}$. 
The kinematics of a growing crack, sliding off by "s" and shear cracking by "c", gives the CTOA in terms of the ratio of sliding to cracking $s /(s+c)$ and the slip angle $\theta_{\mathrm{s}}: \operatorname{CTOA}\left(\mathrm{s} /(\mathrm{s}+\mathrm{c}), \theta_{\mathrm{s}}\right)$. The ratio $\mathrm{s} /(\mathrm{s}+\mathrm{c})$ is the fracture shear strain $\gamma_{\mathrm{f}}$, which in turn depends on the stress triaxiality $s / k$, where $k$ is shear strength [20].

Incorporating this dependency into the previous expression gives CTOA $\left(\theta_{\mathrm{S}}, \sigma_{\mathrm{S}} / \mathrm{k}\right.$, material parameters).

Kim and McClintock [21] developed a rigid-plastic, line-spring element for through-cracking of deeply-cracked surface cracks in plates from slip-line field analysis, which provides the parameters $\theta_{S}$ and $\sigma_{S} / k$, and hence CTOA, in terms of the relative tension and bending applied to the ligament. This element will be incorporated into ABAQUS with help from Lee.

\section{PROPOSED PLANS FOR THE YEAR IAN. 1, 1992 - DEC. 31,1992}

- We will complete our analyses of parametric limits of two-parameter $(J, T)$ descriptions of crack tips, establishing guidelines for their use.

- Enhancements to the elastic-plastic line-spring finite element. Stationary crack studies will be completed and reported. The treatment of constraintsensitive through-thickness cracking will be included in the line-spring, basied on the deep-cracked micromechanical model, on the fully-plastic triaxiality of the model edge-crack under tension and bending, and on phenomenological correlations of crack triaxiality with $T$. The models of constraint-sensitive cracking will be compared with detailed 2-D finite element simulations and with experimental results underway at INEL on edge-cracks under combinations of tension and bending. Surface-crack growth predictions will be compared with previous INEL experimental data. Preliminary applications of the model will be made to structural crack configurations such as the circumferentially surface-cracked pipe in bending.

- Refinement of the micro mechanical CTOA model. The approximate functional form of the micro-mechanical expression for CTOA will be refined to explicitly include a hardening coefficient $(n)$ and a damage parameter $(\eta)$ : CTOA $\left(\theta_{S}, \sigma_{S} / k, n, \eta\right)$.

- Finite element computations of crack growth. Plastic crack growth elements (PCGE), which include crack tip position as an internal parameter, will be further developed to allow coarser meshes for routine crack growth simulations. Finite element computations using the PCGE will be performed to compare with the rigid-plastic line spring element formulation and with fine-scale FE modeling. 
- Interpretation of 3-D fracture surface observations. We will cooperate with $R$. Lloyd of INEL on the effects of deformation during fracture on the reconstruction of the fracture process from 3-D fracture surface observations. This study will be based on the sliding off and shear cracking cracking crack growth model. Consideration will be given to fractures near weldments.

- Development, analysis, and exploratory testing of low constraint crack geometries. Although many practical fracture applications occur with low crack triaxiality, test specimens for obtaining low constraint have experimental drawbacks. It is difficult to accurately control crack front location, straightness, etc., in shallow bend bars $(a / w<0.2)$. Center cracked tension requires large loads, and has two (generally unequal) crack fronts. Based on slip-line concepts, we believe that easy-to-test specimen geometries can be developed in which desired levels of crack triaxiality can be "tailored" by geometric modification.

- $\quad$ Cracking in plastically heterogeneous media. We will analyze the INEL experiments on alloy titanium which is bonded to (much softer) commercially pure titanium, in simulation of cracks near regions of large strength differences, such as in small regions near weldments.

\section{REFERENCES}

1. Wang, Y.-Y., D.M. Parks, W.R., Lloyd, W.G. Reuter, and J. Epstein. "ElasticPlastic Deformation in Surface-Cracked Plates: Experiment and Numerical Analysis," ASME Journal of Applied Mechanics, 1991, in the press.

2. Parks, D.M. and Y.-Y Wang. "Elastic-Plastic Analysis of Part-Through Surface Cracks." In Analytical, Numerical, and Experimental Aspects of Three-Dimensional Fracture Processes, eds. A.J. Rosakis et al., ASME AMD91, ASME, New York, NY, 1988, pp. 19-32.

3. Wang, Y.-Y. "On the Two-Parameter Characterization of Elastic-Plastic Crack-Front Fields in Surface-Cracked Plates," presented at ASTM Symposium on Crack Constraint, Indianapolis, Ind., May 1991, to appear, Proceedings.

4. Parks, D.M. "Three-Dimensional Aspects of HRR-Dominance," in Defect Assessment in Components - Fundamentals and Applications, K.-H. Schwalbe and J.G. Blauel, Eds., Mechanical Engineering Publications, London, 1991, pp. 206-231.

5. Hancock, J.W., W.G. Reuter and D.M. Parks. "Constraint and Toughness Parameterized by $\mathrm{T}$," presented at ASTM Symposium on Crack Constraint, Indianapolis, Ind., May 1991, to appear, Proceedings. 
6. Wang, Y.-Y. and D.M. Parks. "Evaluation of the Elastic T-Stress in SurfaceCracked Plates Using the Line-Spring Method," to appear, International Journal of Fracture.

7. Rice, J.R. and N. Levy. "The Part-Through Surface Crack in an Elastic Plate," Journal of Applied Mechanics, v. 39, 1972, pp. 185-194.

8. Nakamura, T. and D.M. Parks. "Determination of Elastic T-Stress Along 3D Crack Fronts Using An Interaction Integral," MIT Report, July 1991; submitted to International Journal of Solids and Structures.

9. Kfouri, A.P. "Some Evaluations of the Elastic T-term Using Eshelby's Method," International Journal of Fracture, v. 30, 1986, pp. 301-315.

10. Nakamura, T. and D.M. Parks. "Anti-symmetrical 3-D Stress Field Near the Crack Front of a Thin Elastic Plate." International Journal of Solids and Structures, v. 25, 1989, pp. 1411-1426.

11. Nakamura, T. and D.M. Parks. "Three Dimensional Stress Field Near the Crack Front of a Thin Elastic Plate." ASME Journal of Applied Mechanics, v. 55,1988 , pp. 805-813.

12. Nakamura, T. and D.M. Parks. "Three-Dimensional Crack Front Fields in a Thin Ductile Plate," Journal of the Mechanics and Physics of Solids, v. 38, 1990, pp. 787-812.

13. Wang, Y.-Y. "A Two-Parameter Characterization of Elastic-Plastic Crack Tip Fields and Applications to Cleavage Fracture," Ph.D. Thesis, MIT, May 1991.

14. Betegon, C. and J.W. Hancock. "Two-Parameter Characterisation of ElasticPlastic Crack Tip Fields and Associated Failure Criterion," in ECF8 Fracture Bchavior and Design of Materials and Structures, Vol. II, Ed. D. Firraro, EMAS Ltd., Warley, UK, 1990, pp. 999-1002.

15. Sumpter, J.D. (1991). To appear, Proceedings ASTM Symposium on Crack Constraint, Indianapolis, May 1991.

16. Parks, D.M. and C.S. White (1982). "Elastic-Plastic Line-Spring Finite Elements for Surface-Cracked Plates and Shells," ASME Journal of Pressure Vessel Technology, v. 104. pp. 287-292.

17. Hibbitt, Karlsson and Sorensen, Inc. (1990). ABAQUS User's Manual, HKS, Inc., Providence.

18. Rice, J.R. (1972). "The Line-Spring Model for Surface Flaws," in The Surface Crack: Physical Problems and Computational Solutions, Ed. J.L. Swedlow, ASME, New York, pp. 171-185. 
19. Gudmundson, P. "Validity of Asymptotic Crack Tip Solutions for Plastic Materials," Advances in Fracture Research, Proceedings of the 7th International Conference on Fracture, 1989, V. 1, pp. 315-322.

20. McClintock, F.A., S.M. Kaplan, and C.A. Berg. "Ductile Fracture by Hole Growth in Shear Bands," International Journal of Fracture Mechanics, v. 2, 1966, pp. 614-627.

21. Kim, Y.J. and F.A. McClintock. "Crack Growth in Rigid-Plastic, NonHardening Materials," Res. Memo., Fatigue and Plasticity Lab, Dept. of Mechanical Engineering, MIT, 1991.

\section{RECENT PUBLICATIONS}

McClintcck, F.A., Y.J. Kim and Z.M. Zheng. "Data Needed to Predict Fully Plastic Crack Formation and Continued Growth," invited paper 1991 SEM Spring Conference on Experimental Mechanics, Milwaukee, Wisconsin, June 10-13, 1991. Proceedings pp. 71-77.

Parks, D.M. "Engineering Methodologies for Assessing Crack Front Constraint," presented at 1991 SEM Spring Conference on Experimental Mechanics, Milwaukee, Wis., Jure 10-13, 1991. Proceedings pp. 1-8.

Parks, D.M. "Three-Dimensional Aspects of HRR-Dominance," in Defect Assessment in Components - Fundamentals and Applications, ESIS/EGF9, J. G. Blauel and K.-H. Schwalbe, Eds., Mechanical Engineering Publications, London, 1991, pp. 206-231.

Wang, Y.-Y. "On the Two-Parameter Characterization of Elastic-Plastic CrackFront Fields in Surface-Cracked Plates," presented at ASTM Symposium on Crack Constraint, Indianapolis, Ind., May, 1991, to appear, Proceedings.

Wang, Y.-Y. and D.M. Parks. "Evaluation of th. Elastic T-Stress in Surface-Cracked Plates Using the Line-Spring Method," to appear, International Journal of Fracture.

Nakamura, T. and D.M. Parks. "Determination of Elastic T-Stress Along 3-D Crack Fronts Using An Interaction Integral," submitted to International Journal of Solids and Structures, July, 1991.

Hancock, I.W., W.G. Reuter and D.M. Parks. "Constraint and Toughness Parameterized by T," presented at ASTM Symposium on Crack Constraint, Indianapolis, Ind., May 1991, to appear, Proceedings.

Wang, Y.-Y., D.M. Parks, W.R. Lloyd, W.G. Reuter, J. Epstein. "Elastic-Plastic Deformation in Surface-Cracked Plates: Experiment and Numerical Analysis," presented at 1991 ASME Applied Mechanics and Biomechanics Summer Conferenie, Columbus, Ohio, June 17-19, 1991, Journal of Applied Mechanics, in the press. 


\section{COMMINUTION OF ENERGY MATERIALS}

\section{PERSONNEL}

Faculty: $\quad$ C.R. Peterson, Department of Mechanical Engineering

F.A. McClintock, Dept. of Mechanical Engineering

H. Kytomaa, Department of Mechanical Engineering

Graduate Students: Karen Annis

Chahid Ghaddar

Satya Deb Misra

\section{ABSTRACT}

Comminution, the reduction of coarse solids to fine particles, is a necessary step in coal cleaning and ore beneficiation, perhaps including oil shale. It is also a notoriously energy intensive process, particularly when grinding to the very small sizes necessary for deep cleaning of coal or for beneficiating lowgrade ores. Comminution of material within deep particle beds is necessary for processing of sufficient mass flows of material. This project seeks to develop, through combined analytical and experimental work, an understanding of particle fracture and material transport mechanisms within such beds in order to develop designs of substantially increased efficiency. Computer simulation of beds of spherical particles has provided a clear picture of crushing behavior within beds. Experimental work with particle beds has qualitatively confirmed the simulation and provided quantitative data on crushing efficiency. Preliminary fluidized bed experimental work has demonstrated effective separation of fine material from coarse, an essential capability for the development of higher efficiency processes. Continuing analytical and experimental work will focus on the material transport and size separation behavior within fluidized beds suitable for use in a crusher. A novel crusher/material transport concept has evolved from this work and will continue to serve as a practical guide for these basic studies.

\section{GOALS}

The ultimate goal of this program is to design substantially more efficient means to grind materials to very small sizes, perhaps as small as 10 microns. Complex behavior in both crushing and material transport phenomena, and in their interaction, renders the process too complex for purely empirical progress on the one hand or for realistic analytical description on the other. The goal of this basic research program, then, is to gain an understanding of the phenomena, using experimental work in conjunction with analytical modeling to describe observed behavior in basic physically sound terms. A physically correct 
understanding, even if simplified, is essential if substantial performance gains are to be achieved. In fact, the understanding developed thus far has indeed pointed the way to promising practical approaches.

\section{PROGRESS}

Earlier accounts have described the development of a computer simulation of a two-dimensional bed made up of three-dimensional spheres, and of single-particle experimental tests to derive a suitable failure criterion for spheres subjected to multiple loadings as would occur within a particle bed. For brittle materials, the simplest possible failure criterion, a size-dependent critical load at any of the multiple contact points, proved appropriate in single-particle tests, and it also provided the best correlation between experimental and simulated bed behavior.

More recent experimental bed testing has defined a simple measure of "bed efficiency" and shed some important quantitative light on efficient behavior. Fracture of an individual particle between parallel plates is in itself an inefficient process since elastic energy stored within the stressed particle is more than enough to fracture the particle once a fracture is initiated." In a search for the additional losses which occur prior to and during fracture of an individual particle within a particle bed, a "bed efficiency" was defined as follows:

$$
\eta_{\text {bed }}=\frac{\text { energy to fracture a single particle between flat plates }}{\text { energy to fracture a single particle within a particle bed }}
$$

As defined and measured experimentally, this efficiency treats only the "primary" or initial fracture of a particle, and it ignores additional useful work in the secondary fracturing of primary fracture fragments. Further, it does not consider variations in fracture effectiveness in the sense of favorable (i.e., small) fragment sizes. Still, the definition is useful at least as a first approximation, as it appears that there is very little secondary fracturing (in a bed consisting initially of roughly uniform spheres) at least up to that compression for which all spaces between unbroken spheres are filled with fragments from broken spheres. Bed efficiency rises from zero at very small compressions (losses due to relative motion of particles with no useful fracturing) to about 40 percent at compressions of about $18 \%$. This compression corresponds roughly to the complete filling of voids between spheres by fragments from primary fractures. Bed efficiency is also dependent upon bed height, falling rapidly from 100 percent (by definition) for a monolayer of spheres to about 40 percent for a five-diameter

\footnotetext{
" except for extremely small particles which, having a large surface-to-volume ratio, store insufficient energy to complete fracture upon initiation.
} 
deep bed."* Bed height appears to remain at about this level for much thicker beds, provided one starts with a bed of approximately uniform spheres (1.7 to 2.0 $\mathrm{mm}$ in these tests) and provided one crushes to that degree (approximately $18 \%$ reduction in thickness) necessary to achieve maximum efficiency. Continued bed compression beyond this optimum level is accompanied by a rapid decline in bed efficiency since, although primary fracturing continues unabated, work input rises sharply as crushing stress rises rapidly once all inter-particle volume is filled with the fragments of prior primary fractures. This behavior, with bed efficiency falling only to about $40 \%$, and thereafter remaining at that level for much thicker beds bodes well for productive machines. This relatively high efficiency does, however, require that the particle bed be eisentially free of fine materials at the start of the compression stroke.

Preliminary compression tests of similar sized $(1.7-2 \mathrm{~mm})$ granular material (sand) indicated qualitatively similar behavior, although the zones of compaction, crushing at roughly constant compressive load, and rapidly rising load are not as distinctly evident.

Effective, prompt removal of fine material directly from the crushing region is the key to sustained high efficiency-a perhaps not surprising observation. This prompted the study of material transport via fluidized flow phenomena. It is known that small spheres (having a larger drag-to-weight ratio) are more easily fluidized than large ones. Early fluidized flow-supported bed tests confirmed a strong capability to separate small from large particles. Later, more quantitative tests confirmed this behavior and provided some quantitative data on rates of particle segregation according to particle size. Time for complete segregation of a five-inch high bed of mixed $2 \mathrm{~mm}$ and $.8 \mathrm{~mm}$ pirticles was excessive (greater than 10 seconds) for a realistic application. Fiowever, it will not be necessary to wait for complete segregation in a particle device. Other observations from early tests suggest that it will not be possible to employ an upwardly divergent fluidized flow, and that the fluidized region must be essentially vertical.

Attempts to explore this experimental approach and the overall crushing/material-transport concept with industry people have met with what might be called passive resistance. While granting that separation of fine material is an important goal, industry "researchers" expressed the typical opinion that a research program is not worthwhile unless it can be proven that it will succeed. The fluidized bed transport concept has not been proven to work in a crushing device; therefore, it is not a viable research direction. While this typical attitude does not bode well for U.S. industry, it does confirm the need for other leadership in sponsored research and for a basic approach that does not depend for success upon an ill-informed, cut-and-try design approach that may well be limited to one try.

\footnotetext{
*" Prior writings, which described an unexplained reversal of this logical behavior, with bed efficiency declining continuously with bed height, were in error on this point.
} 
Though there is certainly much that remains to be learned regarding bed crushing behavior (particularly beds of granular material), it is clear that our knowledge of this behavior greatly exceeds our knowledge of size-dependent material transport phenomena. For example, in addition to the anticipated importance of removing fine material, our crushing tests have shown that, for spherical material at least, beds of arbitrary thickness will retain acceptable (40\%) bed efficiency, that maximum efficiency is attained at about 18 percent compaction of the bed, and that roughly $40 \%$ of the particles will be fractured in a single compression stroke at that compaction.

To gain comparable understanding of size-dependent material transport phenomena, the program will now shift to a study of fluidized separation of particles according to size. Work to date has been of the "batch" variety, measuring the flow parameters and time to achieve separation of an initially mixed bed of $2 \mathrm{~mm}$ and $.8 \mathrm{~mm}$ spheres. Constant velocity flow and slowly pulsating flows (one second on, one second off) have been observed, and it is noted that pulsations at this frequency do not change the total "on" time to achieve separation. Future tests will include continuous, truly steady conditions to determine the upward velocity of smaller spheres within a fluidized bed of larger spheres, to explore the influence of rapidly pulsating flows comparable to the high frequency motion of a crushing machine, and the influence of laterally moving walls. These latter tests will be "steady" in an average sense, though unsteady when view ad for very short durations.

Existing batck.process apparatus will be replaced by new equipment capable of sustaining steady flows. For example, a bed of coarse material may be maintained in a stationary, fluidized condition while through flows of various sizes of smaller particles are transported through the bed. This will require systems to feed the smaller material into the incoming fluid flow and to retain and recycle that material after passing through the test chamber. Fluid flows might be completely steady or with a superimposed high-frequency oscillation to explore behavior which might occur within a crushing device. It may also be possible to oscillate the test region walls to stimulate crushing action, though it is not yet the intent to actually crush material between converging walls.

While proposals for funding a cooperative effort at INEL in acoustic monitoring of crushing action have not been successful, it is worth noting that this remains a highly desirable effort. Acoustic monitoring would simplify crushing experimental work and it is also likely that it would provide entirely new information.

\section{RECENT REFERENCES}

Annis, Karen, "Segregation Control of Binary Size Particles in a Comminution Device", S.M. Thesis, Mechanical Engineering Department, MIT, August 1991. 
Ghaddar, Chahid, "Fracture Efficiency within Particle Beds", S.M. Thesis, Mechanical Engineering Department, MIT, January 1991,

Misra, Satya Deb, "Particle Breakage and Material Transport in the Design of High-Efficiency Comminution Device", S.M. Thesis, Mechanical Engineering Department, MIT, February 1991. 


\section{Engineering Analysis}




\section{SYNTHESIS AND OPTIMIZATION OF INTEGRATED CHEMICAL PROCESSES}

\section{PERSONNEL}

Faculty:

Lawrence B. Evans, Department of Chemical Engineering

Graduate Students:

Suresh Sundaram

Juan Gomez

\section{ABSTRACT}

This research is aimed at developing improved computer methodologies for the design of integrated batch and continuous chemical processes. Batch processes are becoming increasingly important because of the increased emphasis of the chemical processing industry on higher value specialty chemicals. Methods for computer-aided synthesis and optimization of batch chemical processes have yet to reach an advanced state of development. Generic methodologies for simulation, optimization, and synthesis of batch processes will form the technology base on which the computer-aided engineering tools of the future need to be developed. This research is aimed at solving some key problems in this field.

In the area of continuous processes, work is focused on synthesizing processes with improved energy integration. The classical approach to complete flowsheet synthesis has been to decompose the problem into chemical process design, heat exchanger network design, and utility system design. The overall solution using this sequential approach neglects many subsystem interactions leading to inefficient use of capital, raw materials, and energy. This research focuses on developing a methodology for total flowsheet synthesis that takes into account subsystem interactions.

\section{GOALS}

Last year, we proposed a major revision of the project to address methods for synthesis and optimization of batch and semi-continuous processes. To optimize batch processes, a process model that simulates the system behavior must be developed. Modeling batch unit operations is more complex than modeling continuous ones because batch processes are inherently unsteady-state. The describing equations consist of highly nonlinear differential as well as algebraic equations, the equations are "stiff" and require sophisticated algorithms for integration. General purpose dynamic models of unit operations are needed in a form so that they can be conveniently used to simulate and optimize integrated plant systems. The synthesis problem in batch processes is difficult because in addition to the dynamic nature of the unit operations, the number of flowsheet alternatives that need to be evaluated before arriving at the optimal 
flowsheet is large. The synthesis approach can be based on heuristics, on evolutionary rules, or mathematical programming techniques.

In the area of continuous process flowsheet synthesis, heuristics have been traditionally used to account for subsystem interactions. Heuristics can identify attractive and unattractive alternatives, but they cannot generate designs which guarantee that the optimum has been achieved. If a completely mathematical programming approach is used, the combinatorial and nonconvex nature of the problem makes the finding of the optimum impractical, even with the most powerful computers available today. A combined heuristic/algorithmic approach is needed where heuristics derived from a thermodynamic understanding of subsystem interactions are used to eliminate unattractive design alternatives at the targeting stage, and mathematical methods are used to find the optimum among the attractive alternatives.

\section{PROGRESS}

Suresh Sundaram completed his doctoral thesis research during the past year (Sundaram, 1991). The objective of his research was to develop a synthesis methodology for batch distillation systems. The insights gained from the solution to this problem will be used to develop methods for other types of batch processes.

Batch distillation is a commonly used method of separating liquid mixtures. Operation of a batch column involves charging the still with the material to be separated and carrying out the fractionation until the desired separation is achieved. During distillation, a variety of discrete events may occur, such as dumping of accumulators and changing operating variables such as the reflux ratio. Composition profiles and operating conditions can change over a wide range of values. The equations which describe the operation of batch distillation are of differential- algebraic form; simulation requires numerical integration of these equations which are usually "stiff". Currently, there exist sophisticated tools for the rigorous simulation of batch columns given feed conditions, column configuration, and operating policy of the column.

There is no systernatic procedure to determine the optimal separation system for separating a multicomponent feed iream into products using batch distillation. For the most part, engineers decide the operating variables (reflux ratio) based on past industrial experience or on heuristics. Optimal reflux ratio policies based on such heuristics can result in excess waste product and can be inefficient. When a single distillation column is to yield multiple products, the choice of the optimal reflux ratio policy and the location of the cuts is made more difficult because of mutual interactions. The sequence of overhead fractions to be taken during distillation must also be selected as part of the optimal separation system. Finally, if there are multiple columns, the assignment of separation steps to columns becomes an added complicating factor. 
Sundaram's thesis addressed the batch distillation synthesis problem for separating a multicomporient feed stream into specified products using available equipment. The proposed solution procedure involves postulating a "superstructure" which has embedded in it all possible alternatives for conducting the desired separation, formulating the proposed superstructure as a mathematical programming problem, and then solving it using available optimization algorithms.

A s'uperstructure was developed for batch separation systems when a single feed is to be separated into products. It allows for the reprocessing of streams, various alternative sequences of overhead fractions, continuous reflux ratio profiles, and the use of multiple columns. An optimization model for the superstructure was derived. The objective function used in the model is maximization of profit. The model allows the presence of various constraints which are typically encountered in a batch environment. For a single column problem, the optimization model is a nonlinear program (NLP); for the multiple column case, the model is a mixed-integer nonlinear program (MINLP).

To solve the batch distillation synthesis problem efficiently and within reasonable computation time, a fast, accurate model for batch distillation simulation using the Fenske-Underwood-Gilliland (FUG) equations of continucus distillation design was developed. The model consists of stepping forward in time using a first- order explicit integration scheme with a variable time step, and solving the FUG equations at each time step. A large number of example problems were used for model testing and validation.

A common method of operation is to use a single batch column to separate multiple products from a single feed by using a "direct" scheme of separation whereby alternate product and waste streams are distilled overhead from the distillation column. Thus, the sequence of overhead fractions is specified. However, it is important to determine the optimal reflux ratio policy that should be used when all the required products are being separated. A nonlinear programming formulation was derived to solve this optimal operations problem. A number of reflux ratio profiles are possible in the formulation: constant during distillation, constant during a cut but varying from one cut to another, and continuously varying profile. For the special case when the reflux ratio is previously specified, the problem was reformulated as a linear program (LP).

The solution to the single column synthesis problem yields the reflux ratio policy during each cut and the location of all the cuts; in addition, the sequence of overhead fractions is also optimally synthesized. The effects of non-zero cleanout costs and intermediate storage costs on the solution procedure are demonstrated.

Finally, Sundaram considered the multiple column synthesis problem. Here, the focus of the thesis has been on identifying some of the fundamental trade-offs involved when multiple columns are used. A heuristic-evolutionary procedure is recommended to solve this particular synthesis problem. 
In the area of continuous flowsheet synthesis, Juan Gomez selected a $\mathrm{PhD}$ project to investigate the simultaneous synthesis of the chemical process, its heat recovery network and the plant utilities system. In this first year of research he completed his doctoral thesis proposal and it was approved by his thesis committee. He has focussed initially on improving the thermodynamic understanding of subsystem interactions. Old and new thermodynamic principles based on pinch technology were used to understand how the costs of heat and power interplay with capital and raw material costs. Useful insights were gained particularly in the design of utility systems.

From this improved understanding, it 'became clear that to design a system that includes subsystem interactions, the mathematical programs currently available need to be extended. For example, Gomez extended the pinch location method to obtain information on how much heat can be added or removed at a given temperature without violating the pinch.

\section{PROPOSED PLANS FOR THE YEAR IAN. 1, 1992 - DEC. 31, 1992}

In the coming year, Juan Gomez' immediate objective will be to extend the pinch location method to calculate the capital cost of the heat exchanger network. This extended method will be implemented in the optimization step of a sequential process simulator and used to fully explore the interactions between the chemical process and the heat exchanger network. A mixed-integer linear programming (MILP) formulation will be developed which will provide the capital and operating costs for the utility systems. The main thesis objective will be achieved by implementing the extended pinch location method and MILP generator and solver at the optimization step of a sequential process simulator.

We also plan on adding a graduate student to replace Suresh Sundaram. The student will likely work in the area of dynamic simulation. We have identified important criteria for the next generation dynamic process simulator suitable for modeling batch chemical processes. These are:

1. Models of individual elements of the flowsheet should be in modular form and generalized for any chemical system.

2. The system should be able to use existing software to compute physical properties efficiently.

3. The system should be able to incorporate existing dynamic models that are already programmed.

4. The system should take advantage of parallel computing architectures, but the code should not require it.

5. The systern should be able to handle large flowsheets. 
To meet these goals, a new modular computational architecture are proposed by Andreas Helget will be used.

An alternative project depends on the $\mathrm{PhD}$ student who joins the project, could be in the area of batch process synthesis. In this case, the design methods of Michael Barrera and the synthesis approach developed by Suresh Sundaram for batch distillation systems will be extended.

\section{RECENT PUBLICATIONS}

Barrera, M.D. and L.B. Evans. "Optimal Design and Operation of Batch Processes," Chem. Eng. Commun., 82, 45-66 (1989).

Musier, R.F.H. and L.B. Evans. "Batch Process Management," Chem. Eng. Prog., 86, 66-77 (1990)

Musier, R.F.H. and L.B. Evans. "Schedule Optimization with Lot Sizing in Chemical Process Plants," AIChE Journal, 37(6), 886-896 (1991).

Barrera, M.D., S. Sundaram and L.B. Evans. "Interactions between Process Performance and the Selection of Equipment Units during the Design of Batch Processes," presented at the Symposium on Batch Process Engineering, AIChE Annual Meeting, Chicago IL, November 11-16, 1990 and submitted for publication in Industrial \& Engineering Chemistry Fundamentals.

Sundaram, S. and L.B. Evans. "Batch Distillation Synthesis," presented at the Symposium on Process Design and Analysis, AIChE Annual Meeting, Chicago IL, November 11-16, 1990.

Helget, A., H.I. Britt, J.F. Boston and L.B. Evans. "The Architecture for a Next Generation Dynamic Process Simulator," presented at the AIChE Annual Meeting, Chicago IL, November 11-16, 1990 (also submitted for publication in Computers and Chemical Engineering).

Barrera, M.D. "Optimal Design and Operation of Batch Processes," PhD Thesis MIT, 1990

Sundaram, S. "Synthesis of Separation Strategies for Batch Distillation," PhD Thesis, MIT, 1991. 
Thermal Plasma Processing 


\section{MATHEMATICAL MODELLING OF PLASMA SYSTEMS}

\section{PERSONNEL}

Faculty: $\quad$ Prof. J. Szekely, Department of Materials Science and Engineering

Graduate Student: Richard Westhoff

\section{ABSTRACT}

A comprehensive mathematical model is being developed to describe the electromagnetic, heat transfer, and fluid flow phenomena in plasma systems. At present a model of the plasma plume as well as the behavior of a non-transferred arc plasma torch has been developed and tested for a torch in the laminar mode of operation. The theoretical predictions of the model are in quite good agreement with experiments taken on this system at INEL. The work on torch behavior is currently being extended to turbulent systems, for which comparison is being performed with measurements made at INEL and other labs. Other work currently in progress includes the modelling of the laminar-turbulent transition of the plasma jet, including engulfment phenomena, and the behavior of particles in such systems.

\section{GOALS}

The purpose of this research is to develop a comprehensive mathematical representation of heat flow, fluid flow, electromagnetic and mass transfer phenomena in thermal plasma systems and to compare the theoretical predictions with experimental measurements. Close interaction with experimentalists at the Idaho National Engineering Laboratory and at other labs is an important part of this project. The measurements help to test and verify the model; at the same time, the modelling work helps in the planning, testing and interpretation of the experimental measurements. Together the models and experiments will provide a better understanding of the physical phenomena that may occur in plasma spraying and plasma synthesis.

\section{PROGRESS}

The major accomplishments in the program to date include the following:

1. We have developed a realistic model for the plasma plume for both the laminar and turbulent conditions, while addressing the following specific issues: 
- swirl,

- intermixing,

- realistic property values,

- realistic boundary conditions, and

- full satisfaction of the heat and mass balances.

2. We have developed a model that describes the plasma-particle interactions for dilute systems, accounting for particle dynamics, and for heat transfer, including melting, solidification, intra-particle conduction, vaporization and evaporation. These results have been compared with the experimental measurements conducted at INEL, with good agreement.

3. We have developed a mathematical model for axi-symmetric transferred arcs. The initial calculations were concerned with welding arcs because of the good data base available for verifying the model, and contributed significantly to the mathematical modelling of gas-tungsten arc welding. This model has been adapted to address the transport phenomena inside the plasma torch.

4. A simplified model of the plasma torch has been developed which, as a preliminary step, provided valuable insight into torch behavior and offered good predictions of the plasma plume behavior for certain systems.

Recent Accomplishments include the following:

5 A model has been developed for the non-transferred arc plasma torch which accounts for the electromagnetic effects. It has offered more complete insights into the torch tehavior including the effect of

- electromagnetic forces,

- swirling flow, and

- variations in the cathode current density.

6. The model has been extended (based on previous work) to account for the effect of mixing in the plume with a dissimilar gas (e.g. nitrogen).

7. A total of eleven papers have been published or accepted since 1989, with two more in preparation. 
In the upcoming year, we plan to do the following:

1. Compare the existing model of the non-transferred arc plasma torch with the new measurements of plasma temperature and velocity taken at INEL, as well as other experimental data to test and verify the model.

2. Continue development of a model for the laminar-turbulent transition which will account for engulfment phenomena. The model will be compared with the experimental CARS measurements made by Jim Fincke at INEL.

3. Update the study of plasma particle interactions based on the new information provided by the models of the plasma torch and that offered by the model of transitional flow in the plume.

4. Complete the writing and defense of a doctoral dissertation by Richard Westhoff: "Modeling the Non-Transferred Arc Plasma Torch and Plume for Plasma Processing" based on the work which has been presented in the previous and forthcoming publications.

While this phase constitutes the formal termination of this project, it is noted that a large amount of work remains io be done in this field. As a result of this project, a significant knowledge base in plasma modelling has been established at M.I.T., which optimally should be used to further advance the science base for plasma processing. For this reason the Principal Investigator of this project will continue to search for funding for the continuation of this work through all available sources.

\section{RECENT PUBLICATIONS}

Dilawari, A.H., J. Szekely and R. Westhoff. "A Comparison of Experimental Measurements and Theoretical Predictions Regarding the Behavior of a Turbulent Argon Plasma Jet Discharging into Air", Plasma Chem. Plasma Proc. 10, No. 3, (1990).

Dilawari, A.H., J. Szekely and R. Westhoff. "An Assessment of Heat and Fluid Flow Phenomena inside Plasma Torches in Non-transferred Arc Systerns," ISIJ International, 30, No. 5, 381, (1990).

Choo, R.T.C., J. Szekely and R.C. Westhoff, "Modeling of High-Current Arcs with Emphasis on Free Surface Phenomena in the Weld Pool," Welding Journal, 69, No. 9, 346-s, (1990). 
Trapaga, G., R. Westhoff, J. Szekely, J. Fincke and D. Swank. "Particle and Temperature Histories in a Plasma Plume: A Comparison of Measurements and Predictions," MRS Symp. on Plasma Processing and Synthesis of Materials III, 190, 191, San Francisco, CA. (1990).

Westhoff, R. A.H. Dilawari and J. Szekely. "A Mathematical Representation of Transport Phenomena inside a Plasma Torch," MRS Symp. on Plasma Processing and Synthesis of Materials III, 190, 213, San Francisco, CA. (1990).

Dilawari, A.H., R. Westhoff, J. Szekely, B.A. Detering, and C.B. Shaw, Jr. "A Comparison of the Experimentally Measured and Theoretically Predicted Temperature Profiles for an Argon Plasma Jet Discharging into a Nitrogen Environment," MRS Symp. on Plasma Processing and Synthesis of Materials III, 190, 199, San Francisco, CA. (1990).

Westhoff, R. and J. Szekely. "A Model of Fluid, Heat Flow and Electromagnetic Phenomena in a Non-Transferred Arc Plasma Torch" Accepted in the Journal of Applied Physics, (1991).

Westhoff, R., G. Trapaga, and J. Szekely. 'Plasma-Particle Interactions in Plasma Spraying Systems", Accepted in Met. Trans., (1991).

Chon, R.T.C., J. Szekely and R. Westhoff. "On the Calculation of the Free Surface Temperature of Weld Pools from First Principles: Part I, Modelling the Welding Arc", Accepted in Met. Trans., (1991).

Westhoff, R. and J. Szekely. "A Moclel of an Argon Plasma Torch Discharging into Nitrogen", To be published in Proceedings of the International Symposium: "Thermal Plasma Applications in Materials and Metallurgical Processes", San Diego. (1992).

Szekely, J. and R.C. Westhoff. "Recent Advances in the Mathematical Modelling of Transport Phenomena in Plasma Systems", To be published in Proceedings of the International Symposium: "Thernal Plasma Applications in Materials and Metallurgical Prociesses", San Diego. (1.992). 

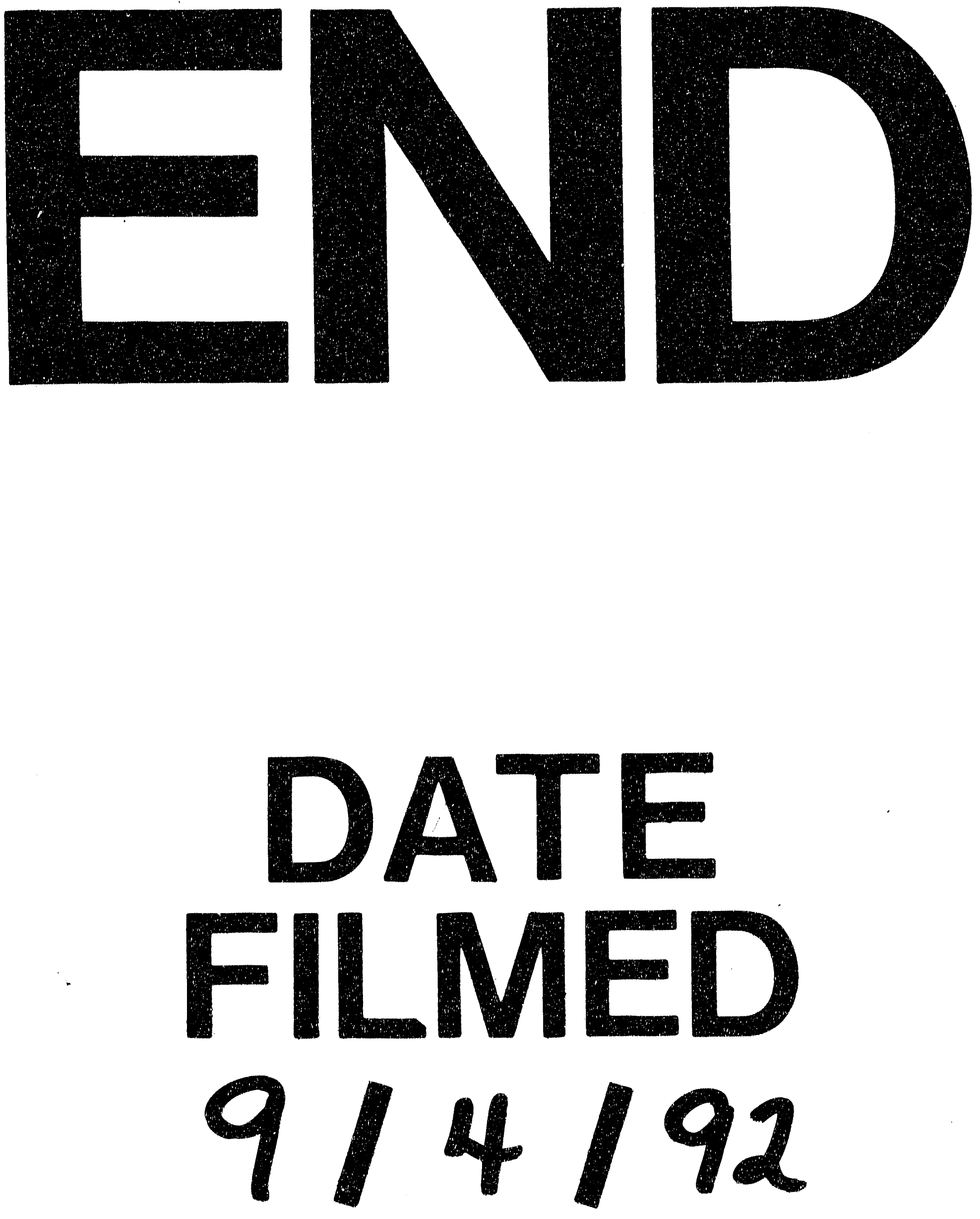
